\title{
ArcheoSciences
}

Revue d'archéométrie

33 (suppl.) | 2009

Mémoire du sol, espace des hommes

\section{Investigating ancient landscapes and settlement patterns in the Chengdu Plain, Sichuan, China}

Timothy J. Horsley, Rowan K. Flad, Gwen P. Bennett, Li Shuicheng, Jiang Zhanghua and Pochan Chen

\section{(2) OpenEdition}

12 Journals

Electronic version

URL: https://journals.openedition.org/archeosciences/1557

DOI: 10.4000/archeosciences. 1557

ISBN: 978-2-7535-1599-4

ISSN: $2104-3728$

Publisher

Presses universitaires de Rennes

Printed version

Date of publication: 30 October 2009

Number of pages: $187-190$

ISBN: 978-2-7535-0943-6

ISSN: 1960-1360

\section{Electronic reference}

Timothy J. Horsley, Rowan K. Flad, Gwen P. Bennett, Li Shuicheng, Jiang Zhanghua and Pochan Chen, "Investigating ancient landscapes and settlement patterns in the Chengdu Plain, Sichuan, China", ArcheoSciences [Online], 33 (suppl.) | 2009, Online since 30 October 2011, connection on 01 February 2022. URL: http://journals.openedition.org/archeosciences/1557 ; DOI: https://doi.org/10.4000/ archeosciences. 1557 


\title{
Investigating ancient landscapes and settlement patterns in the Chengdu Plain, Sichuan, China
}

\author{
Timothy J. Horsley*, Rowan K. Flad **, Gwen P. Bennett***, \\ Li Shuicheng ${ }^{* * * *}$, Jiang Zhanghua ${ }^{* * * * *}$ and Pochan Chen ${ }^{* * * * * *}$
}

Key words: China, Landscape, Magnetometer, Settlement patterns, State formation.

\section{INTRODUCTION}

This paper introduces an integrated survey methodology that is being employed by the Chengdu Plain Archaeological Survey (CPAS) to examine settlement patterns in the context of natural and social landscapes in Sichuan Province, China. The discoveries of the Bronze Age sites of Sangxingdui and Jinsha in the Chengdu Plain have raised questions about the emergence of a complex society in this region, especially as it compares with other societies in the Yellow River valley in Northern China. However, almost nothing is known of the political, social, or natural landscapes associated with this initial state formation. This project aims to assess the processes of landscape transformation and related social developments for the periods prior to, contemporaneous with, and following the emergence of complex society in the Chengdu Plain (Flad 2008).

This paper describes the archaeological survey methods being adopted in this challenging landscape of rice paddy agriculture and rapid urban development, with a particular focus on the magnetometer surveys. Preliminary results indicate their potential for detecting prehistoric and historic remains and subsurface geomorphological features, thereby augmenting the findings from other survey methods.

\section{BACKGROUND TO THE SURVEY AREA}

This project is centred on the Gucheng site in Pi Xian County, one of nine late Neolithic walled enclosures found scattered throughout the Chengdu Plain (Wang Yi 2006). The survey region covers an area of $314 \mathrm{~km}^{2}$ around the Gucheng to focus on the nature and pattern of settlements from the Neolithic (ca. 3000-1500 B.C.), Bronze Age (ca. 1500-200 B.C.) and Han periods (ca. 200 B.C. -200 A.D.).

The fertile alluvial deposits of the Chengdu Plain have made it an important region for rice cultivation, resulting in an intensely altered landscape. Many rivers and streams have been channelized to facilitate water management; the rice paddies are flooded during the summer and then drained for growing vegetables through the winter months. This situation presents a challenge for archaeological prospection methods. Not only is the modern landscape highly modified

* Museum of Anthropology, The University of Michigan, USA. (timhorsley@gmail.com)

** Department of Anthropology, Harvard University, USA.

*** Department of Art History and Archaeology, Washington University, St. Louis, USA.

**** Department of Archaeology and Museology, Peking University, China.

***** Chengdu City Institute of Archaeology, Sichuan, China.

****** Department of Anthropology, National Taiwan University, Taiwan. 
by intensive cultivation practices, it also results in severely limited surface visibility for much of the year. During the winter, when the CPAS fieldwork is carried out, the farmers use all available land to grow vegetables as cash crops (see Fig. 1).

Further land alteration is due to rapid urbanization in the region. This both threatens the survival of many of these early sites and will also prevent any future meaningful landscape study, highlighting the importance of this current project.

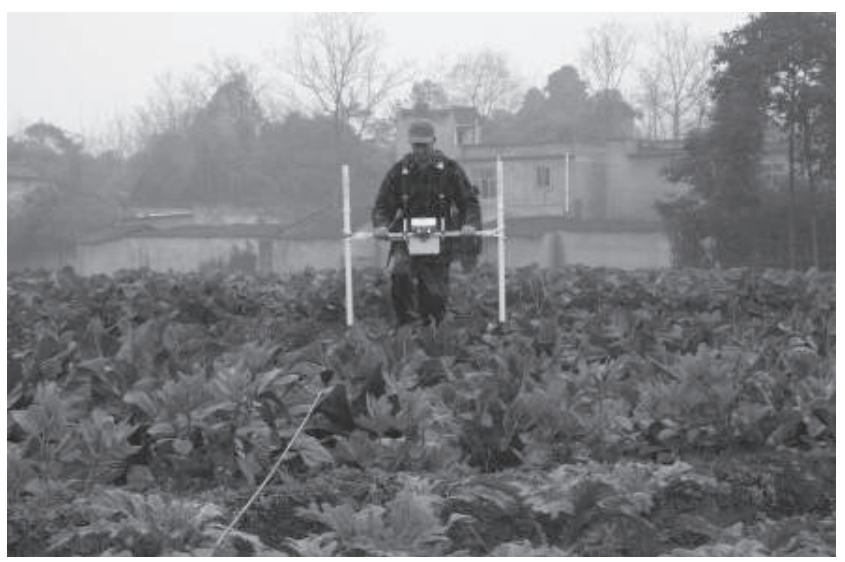

Figure 1: Typical ground conditions for archaeological survey in the Chengdu Plain. The Bartington Grad601-2 dual fluxgate gradiometer is shown here being carried through a field of dense vegetables. The low earthen bank of a paddy wall can be seen running across the foreground.

\section{Methodology}

A regional archaeological survey over a landscape with limited surface visibility requires sampling and an integrated approach. Following an assessment of a number of different prospection techniques in this environment, an effective methodology was devised that combines surface survey, augering and geophysical survey (Chengdu et al. 2009; Horsley 2009). These methods operate on different scales and, when integrated, allow the location, delimitation and characterization of buried archaeological sites, in addition to providing information about the local geomorphology.

\section{(i) Surface Survey}

Field walking is being conducted over the entire $314 \mathrm{~km}^{2}$ to provide full coverage of the region. Any artefacts found on the ground surface or in terrace faces are collected and
GPS coordinates recorded. These finds are later identified, dated and their locations plotted in a GIS. The surface survey is producing an overall picture of the larger sites and features in this landscape and ensures that the major localities are discovered. However, the limited visibility necessitates a sub-surface component to the survey.

\section{(ii) Augering}

The surface survey data are being complemented with an auger survey operating along traverses within the project area. At $200 \mathrm{~m}$ intervals, teams with bucket augers are recording soil profiles and collecting artefacts to allow a representative sample of material from preserved subsurface strata to be analysed. Where anthropogenic material is recovered, the team spread out at $20 \mathrm{~m}$ intervals to determine the extent of activity. This method is allowing archaeological sites to be accurately located and dated; furthermore, plotting the locations of dateable artefacts in the GIS helps to reveal the extent of occupation areas from different periods.

\section{(iii) Geophysical survey}

Magnetometry has been incorporated into the project as a complementary tool to aid in site characterization and to locate specific features for later excavation by local archaeologists. Following the identification of buried anthropogenic deposits during the surface and auger surveys, a Bartington Grad601-2 dual fluxgate gradiometer is employed to collect data at a resolution of $0.5 \mathrm{~m} \times 0.125 \mathrm{~m}$. As Figure 1 shows, the dense groundcover of vegetables and frequent obstacles such as ditches and raised earth paddy walls severely impact the rate at which data may be collected in this landscape. Despite this, excellent results have been obtained at the 11 sites visited to date.

\section{Preliminary Results}

The site of Majiacun illustrates the sequential survey methodology employed by the CPAS Project. During the surface survey in 2006-7, a small quantity of Neolithic and Han material was recorded close to the modern village. The auger survey also passed through this area and identified Neolithic, Bronze-Age and Han material along this natural ridge. The locations of these find spots and the cores are overlaid onto the magnetometer results in Figure 2.

The magnetometer data from Majiacun are dominated by the well-defined and regular responses to ditches, paddy walls, and other cultivation features. Of archaeological 
Figure 2: Survey results from Majiacun. The locations of material found during the surface and auger surveys are superimposed onto the magnetometer data: circles = Neolithic; squares $=$ Bronze Age; triangles $=$ Han period. The results are overlaid onto a satellite image to aid in the relocation of anomalies.

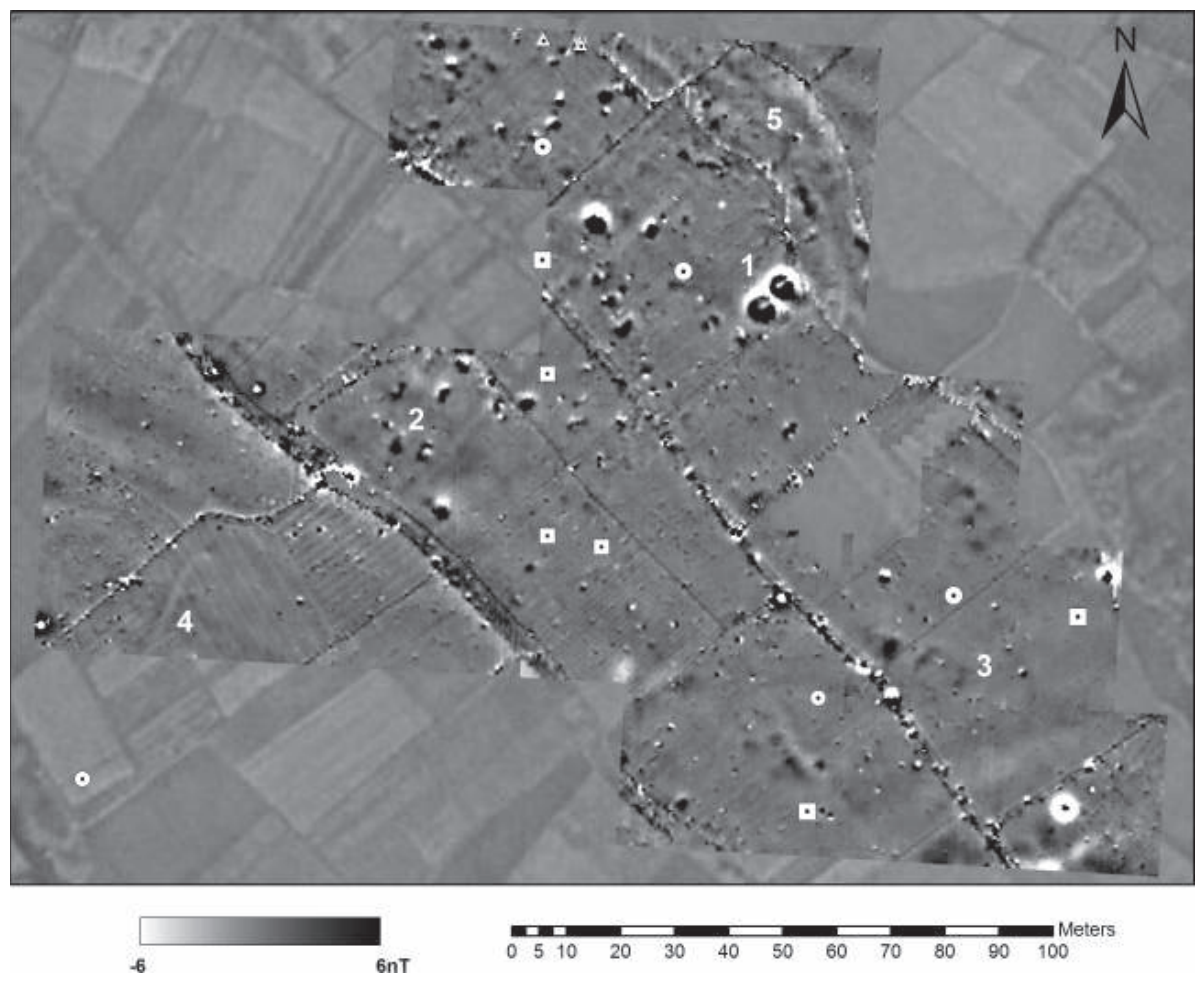

interest are two intense responses at [1] that may either be due to kilns or large brick tombs. Subsequent augering has shown that they are constructed from brick dating to the Han period, and excavation by the Chengdu Archaeological Institute will determine their origin. Brick-built tombs from the Han period more commonly produce less intense and rectangular anomalies, such as those seen at [2]. The weak rectilinear response at [3] is believed to be due to the remains of a house constructed from wattle and daub and burnt down. Augering revealed a burnt clay deposit at a depth of 0.9-1.0m - the same depth as nearby finds of Bronze Age ceramics during the auger survey, suggesting a similar date for the structure. Excavation of this feature is also planned. Other anomalies in the vicinity may relate to pits and additional occupation features.

The magnetometer surveys are also providing evidence for landscape evolution, such as the linear trend at [4] that may represent a buried irrigation ditch In addition, the results are also helping to identify geomorphological features. The course of a former stream was suggested by the meandering field boundaries at [5] and is confirmed by the magnetometer survey.

This environment presents a further challenge regarding the accurate recording of the geophysical survey grid location, especially as it concerns relocating specific anomalies for future excavation. In this rapidly changing landscape no surface features can be assumed to be permanent to tie-in to. Whilst it is possible to employ D-GPS to accurately record the grid coordinates, the local archaeologists do not possess such a system. Fortunately, however, high resolution satellite imagery exists for much of the CPAS project area, and it is a simple task to overlay the magnetometer results by matching field boundaries to their respective anomalies (such as in Fig. 2). These plots can then be taken into the field and used as a guide for recording other tie-in information.

\section{Conclusion}

The results from the first year of this three-year innovative and highly collaborative project are starting to indicate the nature and pattern of settlements in the region, and will aid our understanding of the emergence of social complexity in the Chengdu Plain. Southern Chinese landscapes have long frustrated workers wishing to survey in this region. The methodology described here promises to make a significant impact on archaeological practice in southern China. 


\section{References}

FLAD, R. K., 2008. New Research Exploring the Origins of Sanxingdui. Backdirt: Annual Review of the Cotsen Institute of Archaeology 2008: 30-31.

Chengdu Pingyuan Kaogu Diaochadui, Flad, R.K., Bennett, G., Horsley, T. J. and Wright, J., 2009. Chengdu pingyuan quyu kaogu diaocha (2005-2007) (2005-2007 archaeological survey in the Chengdu Plain). Nanfang minzu kaogu [Southern Ethnoarchaeology]. TBD.
Horsley, T. J., 2009. Diqiu wuli jishu zai Zhongguo Sichuan Chengdu Pingyuan kaogu gongzuo zhong de yingyong 2006 nian 12 yue - 2007 nian 1 yue (The utility of geophysical techniques in China based on archaeological research in the Chengdu Plain, Sichuan, Dec. 2006-Jan. 2007). Nanfang minzu kaogu [Southern Ethnoarchaeology]. TBD.

WANG, Y., 2006. Prehistoric walled settlements in the Chengdu Plain. Journal of East Asian Archaeology 5 (1-4): 109-148. 